\title{
Research on the Intelligent Question - Answering System of Web - based Course for MOOCs
}

\author{
Huifang Xue \\ Xi'an International University; Xi'an, Shaanxi, 710077, China
}

\begin{abstract}
With the development of technology, the form of people access to knowledge is constantly changing. The intelligent question answering system has become the hotspot and difficult point in the current natural language processing field. It not only integrates the current advanced technology, but also focuses on the generation of the answer to the problem described in the natural language. Based on the analysis of the relevant concepts of MOOCs, this paper combines MOOCs with the network course intelligent question answering system. On the basis of analyzing the theoretical foundation of the design, the author designs the intelligent question answering system for the network course, and hopes that it can play the role of the system better.

Keywords: MOOCs, network course intelligent question answering system, design
\end{abstract}

\section{Introduction}

QA system is actually a computer program, which has the ability to analyze and process natural language, which is an important application in natural language processing technology. In the network teaching environment, people can receive education at any time without any limitation of time and space [1] .In this paper, the author introduces the concept and characteristics of the online question answering system. But the network teaching in the provision of convenience at the same time, also encountered a problem is how to achieve online Q \& A. The traditional teaching model between teachers and students can achieve face-to-face 
communication [2], for students in learning problems can be resolved in time. However, due to the online teaching environment cannot be achieved at all times online, so the design of an advanced, in line with the practical application of the network Q \& A system is very urgent.

\section{The MOOC}

Massive Open Online Course (MOOC) is a new online learning mode, which is very different from the traditional online teaching mode. The biggest characteristic of MOOCs is that online learners of online courses are large-scale, which is free and open to the global learners, with obvious spontaneity and sociality.

MOOCs developed since 2007, and gradually formed a different type of platform to the network, tasks, content-based, different types show different characteristics, can be seen in Table 1.

Table 1 MOOCs different classification

\begin{tabular}{|c|c|c|c|}
\hline & $\begin{array}{l}\text { Content-based } \\
\text { Mud lessons }\end{array}$ & $\begin{array}{l}\text { Web - based Mud } \\
\text { lessons }\end{array}$ & Task - based mooc \\
\hline $\begin{array}{l}\text { Characteristics } \\
\text { Analysis }\end{array}$ & $\begin{array}{l}\text { Similar to } \\
\text { classroom } \\
\text { teaching }\end{array}$ & $\begin{array}{l}\text { In the exchange of } \\
\text { knowledge }\end{array}$ & $\begin{array}{lr}\text { Through the } \\
\text { completion } \\
\text { learning tasks to } \\
\text { master skills }\end{array}$ \\
\hline $\begin{array}{l}\text { Theoretical } \\
\text { basis }\end{array}$ & Behaviorism & China Unicom & Constructivism \\
\hline $\begin{array}{l}\text { Course } \\
\text { Organization }\end{array}$ & $\begin{array}{l}\text { Internal } \\
\text { Spontaneous } \\
\text { Organization } \\
\text { and Dynamic } \\
\text { Push of } \\
\text { Learning } \\
\text { Resources }\end{array}$ & $\begin{array}{l}\text { Internal } \\
\text { Spontaneous } \\
\text { Organization and } \\
\text { Dynamic Push of } \\
\text { Learning Resources }\end{array}$ & $\begin{array}{l}\text { Internal Spontaneous } \\
\text { Organization and } \\
\text { Dynamic Push of } \\
\text { Learning Resources }\end{array}$ \\
\hline $\begin{array}{l}\text { Evaluation } \\
\text { method }\end{array}$ & $\begin{array}{l}\text { Machine } \\
\text { evaluation }\end{array}$ & no & no \\
\hline $\begin{array}{l}\text { Typical } \\
\text { Projects }\end{array}$ & Coursera & PLENK & POT cert \\
\hline
\end{tabular}

\section{The design theory basis of intelligent question-answering system for the network course based on MOOCs}

\subsection{The unicom learning theory}

Unicom learning theory that learning is not a personal internalization activities, knowledge is networked, Unicom, and learning behaviour is connected to a 
special node and the source of information process. Under this theory, the intelligent question-answering system for the network-based courses is to connect all the learners' ideas and realize the sharing of knowledge [4].

\subsection{The behaviourism learning theory}

The behavioural learning theory plays an important role in the design and evaluation of the network course. From the design of network courses, can reflect the small steps in the process of teaching principles, Mu course platform on the content of knowledge points to focus on to achieve. From the aspect of evaluation of network course, the evaluation method of network-course intelligent questionanswering system based on Mu-course is mainly based on process evaluation and formative evaluation. The process evaluation is mainly based on on-line test and after-class work, formative evaluation to the final exam or work-based.

\subsection{The constructivist learning theory}

The constructivism learning theory is mainly embodied in the implementation, design and evaluation of the course. In curriculum design, for example, most of the courses on the Mu-Cheng platform are completed by a learning group, which emphasizes the process by which the learner constructs an internal mental process in a specific context of learning.

\section{The design and analysis of intelligent question - answering system for the web course of MOOCs}

\subsection{Design Principles}

(1) The principle of individualization, network course for $\mathrm{Mu}$ Cheng The intelligent question answering system of learners may be from different regions and even countries, the curriculum design must reflect the openness. Learners in the $\mathrm{Mu}$-oriented platform for learning to be highly flexible, the learner can learn according to their own free to grasp the progress of learning. Therefore, it is necessary to consider the multi-level and multi-angle of the intelligent questionanswering system which is designed for the Mu-class network course, not only considering the commonality of the learners, but also considering the individualization of learning.

(2) The principle of situational learning theory on the basis of constructivism, for the course network course intelligent Q \& A system designed to be able to best in a certain real-world context, which help learners deepen the knowledge, knowledge and skills Master has a good help.

(3) The principle of inter-changeability, learners cannot obtain the timely feedback from the learners if they cannot achieve the interaction in the intelligent question and answer system for the online courses. The interaction of intelligent question answering system of network course is mainly embodied in the 
communication between the learner and the platform, the learner and the teacher and the learner. Online Q \& A, online testing and so on in the network course intelligent question answering system, greatly enhanced the system interactive.

\subsection{The system operating mode selection}

The intelligent question answering system for the MOOCs includes the following modules: login module, knowledge base module, knowledge base intelligent expansion module, keyword module, intelligent answering module, assistant answering module, problem management module and system management module. SQL Server2008 is a relational database management system, which supports the standard query language of relational database - Structured Query Language (SQL), which is a database management system, which is a database management system. (Structured Query Language-SQL), supports traditional relational database objects and features, and also supports database replication. In order to ensure the platform-independent of the intelligent question-answering system for the network course, the table of student information in the knowledge table is taken as an example.

Table 2 student information table design

\begin{tabular}{|c|c|c|c|}
\hline Field Name & Types & length & Description \\
\hline ID & int & 4 & Serial number \\
\hline username & nvarchar & 50 & Student 's name \\
\hline psw & nvarchar & 15 & $\begin{array}{c}\text { Student } \\
\text { password }\end{array}$ \\
\hline power & nvarchar & 1 & Student authority \\
\hline email & nvarchar & 0 & Student mailbox \\
\hline
\end{tabular}

The intelligent question answering system, which is designed by this research, uses the network to provide the teaching and answering service. After successfully connecting to the server, the learners can $\log$ on to the network course intelligent question answering system through the Web browser to input and improve the question content. After receiving the question, the server runs the relevant program module for question and answer. On the user level, Web browser is the user layer, its role is to provide the system interface for learners to display, accept the user's input or display the results returned by the server, this layer is not responsible for the interpretation of the meaning. Application layer is responsible for handling the front-end customer layer application request system, which serves as an intermediate link between user and data service layer, the system user's request to generate SQL statements to retrieve or update the database, and return the results to the client. The data service layer provides various types of data access and management in the database.

\subsection{The system implementation}

After completing the system running environment and development tool selection, begin the data realization, the whole process includes database connection and ASP access XML document two aspects. In the user login module, enter the user 
name and password after you can enter the system's main interface, learners can be online questions, browse history, online discussions. If the user wants to get the fastest answer to a question, you can directly enter the keyword module, and then click Retrieve. In the process of a practical problem is that many of the answers to the search will affect the beauty of the entire page, so take the page output, by using ADO Recordset objects in the PageSize, AbsolutePage, PageCount three attributes of the use to achieve paging. In the Auxiliary Q \& A module, if the user in the auto-answer module, the keyword module did not find the answer, the system will also provide online discussion, send e-mail.

In the intelligent Q \& A module, which is the core of the whole system, the techniques involved include word segmentation, similarity computation. In order to ensure the advanced nature of the knowledge, intelligent expansion of the knowledge base must be taken into account in the knowledge base intelligent expansion module. This design server uses XMLHTTP technology to fetch the relevant pages from the network regularly and finish the internal analysis into the knowledge base. , And then experts on the answers to these questions to review, modify, etc., to ensure that the knowledge base can be expanded.

\subsection{Data security control}

In order to ensure the security of the database, set the appropriate permissions for the database user, limiting each user can only access the necessary database, and filter variable input in the presence of illegal characters and improper preparation of unsafe. The contents of the database will be stored in the database after encryption, hoping to protect the system from multiple aspects of personal information and user security.

\section{Conclusion}

On the basis of summarizing the design principles of intelligent questionanswering system for network course based on MOOCs, the author has carried on the research on the network education and the network course instructional design pattern, and has carried on the research and development of the network course intelligent question-answering system. The research finally built a network course intelligent question and answer system model, of which the main module is designed, and take full account of the characteristics and needs of MOOCs. The shortcoming of this study is how to achieve the exchange of voice and how to more effectively understand the meaning of user expression and to achieve more accurate answer extraction.

\section{Acknowledgements}

This work is supported by the special research project of the Education Department of Shaanxi Province of China (No.15JK2133) 


\section{References}

[1] Wang Lihua. The New Development of American "MOOCs" and Its Enlightenment to China - Based on the Interpretation of the Survey Report of Sloan Coalition .College Education Management, 55(12), pp.68-70, 2014

[2] Xiong Haifan. Application of "Mu-class Teaching" in the Innovation of Specialized Education under the Perspective of "Insight": Model, Curriculum and Organization. Audio-Visual Education Research, 8 (5), pp.87- 91, 2013

[3] Yang Manfu, Jiao Jianli. University Teaching, Big Data, Great Transformation-Analysis and Inspiration of the Research Report on "the First Course of Admission". Audio-Visual Education Research, 12(10), pp. 18- 20, 2012

[4] Xiao Zhanjun, Xin Baozhong. Study on the Crisis of College Survival or the Beginning of the Popularization of Higher Education - The Turn and Future of Research and Practice of College Mute Class, 9(6), pp.58- 61, 2011

[5] LI Yayuan. Study on the Current Situation of Research on MOOC in China: Hotspots and Trends - Based on the Co-word Visualization Analysis of the Key Words in CNKI Published in 2009-2014. Audio-Visual Education Research, 8(4), pp.85-87, 2014 